\title{
Investigation on two-body abrasive wear behavior of titanium carbide filled glass fabric-epoxy composites- a Box-Behnken approach
}

\author{
C. Anand Chairman ${ }^{1}$, S. P. Kumaresh Babu ${ }^{1 *}$, Muthukannan DuraiSelvam ${ }^{2}$, K.R.Balasubramanian ${ }^{3}$ \\ ${ }^{1 *}$ Department of Metallurgical and Materials Engineering, National Institute of Technology Tiruchirappalli, INDIA \\ ${ }^{2}$ Department of Production Engineering, National Institute of Technology, Tiruchirappalli- 620 015, INDIA \\ ${ }^{3}$ Department of Mechanical Engineering, National Institute of Technology, Tiruchirappalli- 620 015, INDIA \\ "Corresponding Author: e-mail: babu@nitt.edu, Tel +91-431-2503462, Fax. +91-431-2500133
}

\begin{abstract}
The two-body abrasive wear behavior of Glass-Epoxy (G-E) composites has been evaluated by the addition of Titanium carbide (TiC) as a secondary reinforcement using pin-on disc equipment at an applied load of 5, 10 and $15 \mathrm{~N}$ for various sliding distances $(25,50,75 \mathrm{~m})$ with 400 grit water proof Silicon Carbide $(\mathrm{SiC})$ abrasive paper. By using Box- Behnken design the significant controlling factors and the interactions influencing the weight loss of the composites are identified. The results indicate that the addition of $\mathrm{TiC}$ in $\mathrm{G}-\mathrm{E}$ composite increases the wear resistance considerably. It was found that highest wear resistance of G-E composite was achieved by the addition of $2 \mathrm{wt} . \% \mathrm{TiC}$ in particulate form. The presence of different wear mechanisms were analyzed and supported by SEM-micrographic examinations.
\end{abstract}

Keywords: polymer matrix composites; wear; scanning electron microscopy; Box-Behnken Approach.

\section{Introduction}

There is an increasing demand for polymer composites in industrial applications due to its low density, high strength and stiffness. One of the commonly used composites is glass fabric-reinforced epoxy-based polymer, which possesses better mechanical and tribological properties. Fabric reinforced plastics (FRPs) are used in various abrasive wear situations such as seals in agricultural and mining equipment, vanes and gears, pumps handling industrial fluids, sewage and abrasive-contaminated water, roll neck bearings in steel mills subjected to heat and shock loading, chute liners abraded by coke, coal and mineral ores handling equipment. Wear is defined as damage to a solid surface, generally involving progressive loss of material, due to relative motion between that surface and contacting substance or substances. Abrasive wear is caused due to hard particles or hard protuberances that are forced against and move along a solid surface. Abrasive wear is the most important among all forms of wear because it contributes almost $64 \%$ of the total cost of wear. (Bijwe et al., 2001).Two-body abrasive wear is caused by the displacement of material from a solid surface due to hard particles sliding along the surface or when rigidly held grits pass over the surface like a cutting tool. In practical applications, many components, such as conveyor belt, shuttle, tillage tools and wind blades are subjected to two-body abrasive wear. In three- body abrasive wear, the grits are free to roll as well as slide over the surface. Two-body abrasive wear is a complex process often involving high strain and plastic deformation and fracture of micro volumes of the material, which might be described as the removal of discrete surface by a harder substance which tends to gauge, score or scratch. Four different mechanisms in abrasive wear process are micro ploughing, micro cutting, micro fatigue and micro cracking. Many researchers have studied the two-body wear behavior of polymers and polymer composites extensively. Epoxy matrix reinforced with fillers/fibers possesses very good mechanical and tribological properties (Chand et al., 2000) Fibers occupy the largest volume fraction in a composite laminate and share the major portion of the load acting on a composite structure. In order to get better performance with low cost bi-directional fabric reinforcement offers a unique solution to the ever increasing demands on the advanced materials. For fabrication that compare to other styles, woven fabric are easy to handle. They are gaining popularity because of their balanced properties in the fabric plane. The addition of fillers brings down the consumption of the resin matrix material for better economy. 
It has been reported that tribological behavior of polymer matrix composites can be improved by the addition of inorganic fillers such as graphite, tungsten carbide, molybdenum disulfide etc. Abrasive wear performance of polymer composites can be improved by the addition of fillers/fibers. Carbides, generally, protect the polymer matrix more effectively than oxides. The wear volume loss of particulate reinforced composites was 50 times lower than that of unreinforced epoxy based composite materials (Durand et.al, 1995). Hardness of the material plays a major role in improving the abrasive wear resistance of the composite. The wear resistance of materials is a function of their hardness and elasticity. An enhanced wear resistance was achieved by the addition of $\mathrm{TiC}$ particles. TiC reinforced steel matrix composite exhibit improved wear resistance over its unreinforced counterpart. Titanium carbide is an important material for technological applications because of its high melting point, hardness, elastic modulus, electrical conductivity and low coefficient of thermal expansion. Composite systems consisting of a polymer matrix and particles of titanium carbide have been considered as a novel class of smart materials. TiC particles may sustain external load, while the epoxy matrix may transfer stresses between the fibers. Such a combination is expected to lead to an enhanced wear resistance, Hence, in the present work, glass fabric reinforced in epoxy matrix filled with $\mathrm{TiC}$ filler material have been taken up for investigation. Using Taguchi method (Sahin, 2006) carried out experiments to analyze the influence of applied load, abrasive grain size and sliding distance on weight loss of metal matrix and its composites. From the literature review it is observed that the researchers have studied the wear property of various inorganic fillers (Mohan.et.al, 2010). However, the work on the effect of load, distance and percentage of filler on glass-epoxy composites filled with TiC particles in wear study is limited. The main aim of this investigation is to focus on the effects of parameters such as applied load, abrading distance and percentage of filler on the two-body abrasive wear behavior. In order to have better understanding of the overall system behavior and to determine the weight loss of the composites, Response Surface Methodology (RSM) is used in this experimental work. The experimental trials are performed based on Box-Behnken design which comes under Response Surface Methodology (RSM).

\section{Experimental details}

\subsection{Specimen details}

The composite material consists of bi-directional glass fabric $(360 \mathrm{gsm})$ of about $18 \mu \mathrm{m}$ diameter. The glass fabric which is used as reinforcement is plain and symmetrical. Each warp fiber passes alternately under and over each weft fiber. Bi-functional epoxydiglycidyl ether of butane diol (LY 5052) and cyclo aliphatic amine (HY5052) room temperature cure system were obtained from M/s.HAM, Mumbai, India. The filler material was TiC powder of particle size in the range 4-10 $\mu \mathrm{m}(\mathrm{M} / \mathrm{s}$. Alfa Aesar, Bangalore, India) as shown in SEM image (Fig.1).

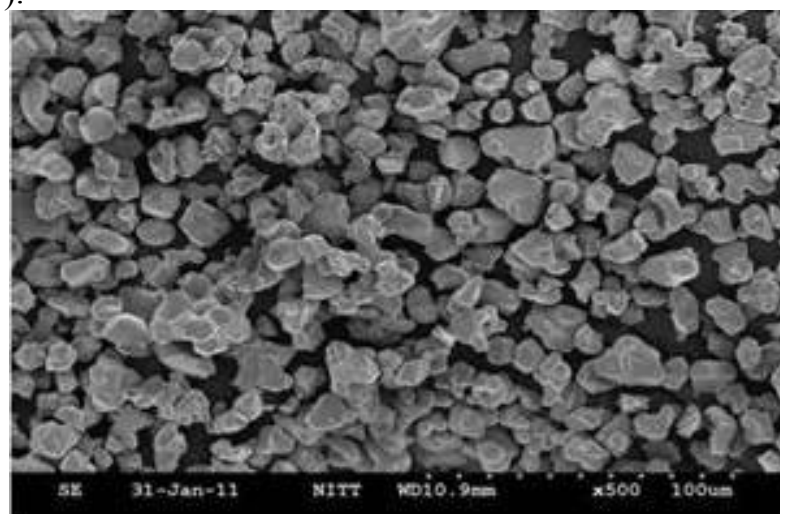

Figure1. SEM image of TiC powder used as filler for composites.

\subsection{Fabrication of composite laminates and preparation of test samples}

The composite fabrication consists of three steps: (a) mixing of the epoxy resin and filler using a mechanical stirrer, (b) mixing of the curing agent with the filled epoxy resin, and (c) fabrication of composites. In the first step, a known quantity of filler was mixed with epoxy resin using a high speed mechanical stirrer. In the second step, the hardener was mixed into the filled epoxy resin using a mechanical stirrer. The ratio of epoxy resin to hardener was 100:38 on a weight basis. In the last step, the epoxy resin was manually smeared onto the glass fabric and the resultant composites were fabricated using the vacuum assisted resin transfer moulding (VARTM) process as described by (Chisholm et al,2004). The composites were cured at room temperature under a pressure of $9.65 \times 10^{4} \mathrm{~N} / \mathrm{m}^{2}$ for $24 \mathrm{~h}$ and it is post cured up to $3 \mathrm{~h}$ at $100^{0} \mathrm{C}$. The glass fiber: matrix (epoxy): filler ratio was $60: 38: 2$ and 60:36:4. The G-E composite and the filler filled composites were prepared in the size of $300 \times 300 \times 3 \mathrm{~mm}^{3}$. The specimens were cut to a size of $5 \times 5 \times 3 \mathrm{~mm}^{3}$ from the plate by using diamond tip cutter. Density of the composites specimens was determined by using a high precision digital electronic weighing balance of $0.1 \mathrm{mg}$ accuracy using Archimedes principle. The details of the composites are shown in Table 1. 
Table 1 Formulations of composite specimen with measured physical properties

\begin{tabular}{ccccccc}
\hline Material details & $\begin{array}{c}\text { Sample } \\
\text { designation }\end{array}$ & $\begin{array}{c}\text { Fiber } \\
\text { (Wt. } \\
\%)\end{array}$ & $\begin{array}{c}\text { Matrix } \\
(\text { Wt. } \\
\%)\end{array}$ & $\begin{array}{c}\text { Filler } \\
\text { (Wt. }\end{array}$ & $\begin{array}{c}\text { Density } \\
(\mathrm{g} / \mathrm{cc})\end{array}$ & $\begin{array}{c}\text { Hardness } \\
\text { Shore-D }\end{array}$ \\
\hline Unfilled G-E & G-E & 60 & 40 & 0 & 1.71 & 83 \\
$2 \%+$ G-E & G-E-1 & 60 & 38 & 2 & 1.73 & 87 \\
$4 \%+$ G-E & G-E - 2 & 60 & 36 & 4 & 1.79 & 85 \\
\hline
\end{tabular}

\subsection{Techniques}

A pin-on-disc instrument (as per ASTM G-99 standard,) is used for two-body abrasive wear tests (Fig. 2). The surface of the $\left(5 \times 5 \times 3 \mathrm{~mm}^{3}\right.$ size) composite specimen was glued to a pin of $8 \mathrm{~mm}$ diameter and $27 \mathrm{~mm}$ length and the other side is in contact with water proof $\mathrm{SiC}$ abrasive paper which is fixed on a rotating disc. The specimens were placed with the plain fabric oriented in parallel to the sliding plane and with the warp parallel to the abrading direction. To make uniform contact with the counter surface; the specimens were polished against a 600 grade $\mathrm{SiC}$ paper. The disc and the specimen surfaces were cleaned with a soft paper soaked in acetone and thoroughly dried before the test. The pin assembly was initially weighed to an accuracy of $0.1 \mathrm{mg}$ in an electronic balance. The difference between the initial and final weights is the measure of weight loss. For each test, minimum three trials were performed and the mean value of weight loss is tabulated. The specific wear rate $\left(\mathrm{K}_{\mathrm{s}}\right)$ was defined as:

$$
K_{s}=\frac{\Delta V}{L X d}
$$

where $\Delta \mathrm{V}$ is the volume loss in $\mathrm{m}^{3}, \mathrm{~L}$ is the load in Newton, and $\mathrm{d}$ is the abrading distance in meters. The surface of the abraded specimens and samples of $\mathrm{SiC}$ abrasive paper were gold sputtered and observed using a scanning electron microscope.

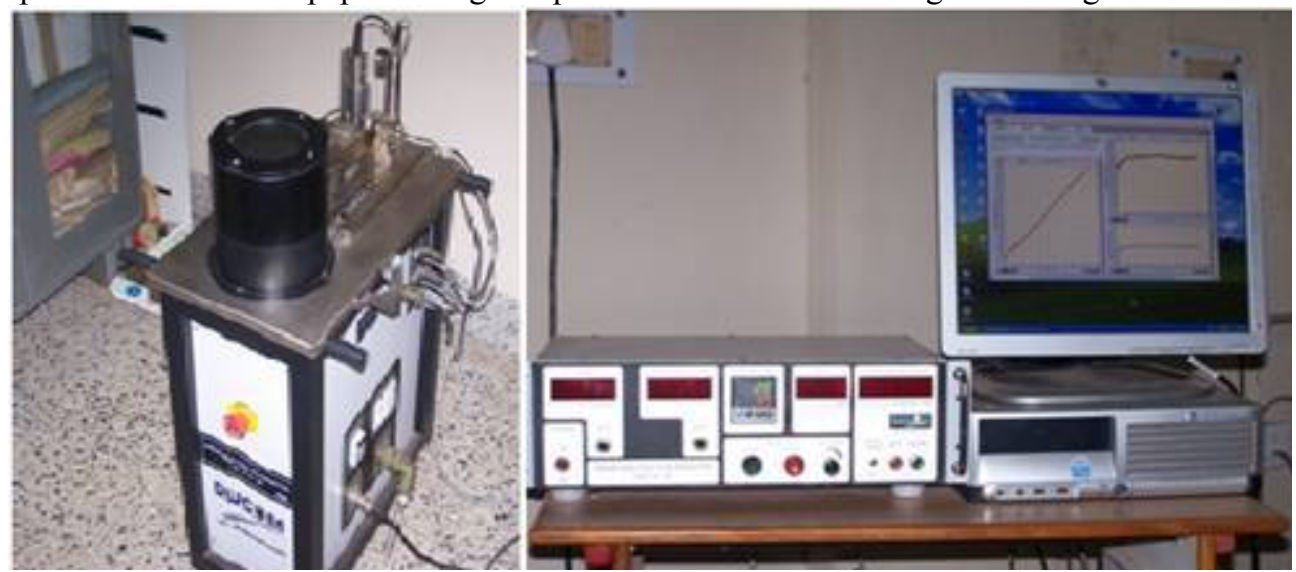

Figure2. A Schematic photograph of pin on disc wear test rig.

\subsection{Identification of predominant factors and finding the upper and lower limits of chosen factors:}

It was reported that the wear rates of the G-E composites are affected by applied load, sliding distance and speed (Kishore et.al. 2005). Among them applied load is an important factor, which increases the wear of G-E composites. The filler types as well as its percentage are response to wear situations in G-E polymer composite system. The predominant parameters that have greater influence on the wear of polymer matrix composite have been identified which are: (i) load, (ii) abrading distance and (iii) percentage of filler. The experimental design level considered for this investigation is shown in Table 2. 
Tables 2 Independent process variables and experimental design levels used

\begin{tabular}{cccc}
\hline Variables & Load(N) & Distance $(\mathrm{m})$ & Percentage of filler (TiC) \\
\hline-1 & 5 & 25 & 0 \\
0 & 10 & 50 & 2 \\
+1 & 15 & 75 & 4 \\
\hline
\end{tabular}

The level for each factor is fixed based on the preliminary investigation. The percentage of filler and applied load was varied between 0 to 4 wt. $\%$ and 5 to $15 \mathrm{~N}$, respectively. The abrading distance is varied from $25 \mathrm{~m}$ to $75 \mathrm{~m}$. Each factor was coded as the low (-1), medium (0) and high (1).The Box-Behnken design requires 12 design points plus 5 center runs, and hence, the number of trials is 17 which is shown in Table 3 .

Tables 3 Design matrix for weight loss

\begin{tabular}{cccc}
\hline Standard run order & Load & Distance & Percentage of filler (TiC) \\
\hline 1 & 5 & 25 & 2 \\
2 & 15 & 25 & 2 \\
3 & 5 & 75 & 2 \\
4 & 15 & 75 & 0 \\
5 & 5 & 50 & 0 \\
6 & 15 & 50 & 4 \\
7 & 5 & 50 & 4 \\
8 & 15 & 50 & 0 \\
9 & 10 & 25 & 0 \\
10 & 10 & 75 & 4 \\
11 & 10 & 25 & 4 \\
12 & 10 & 75 & 2 \\
13 & 10 & 50 & 2 \\
14 & 10 & 50 & 2 \\
15 & 10 & 50 & 2 \\
16 & 10 & 50 & \\
17 & 10 & 50 & \\
\end{tabular}

\subsection{Design of Experiments}

RSM is a collection of statistical and mathematical techniques useful to develop, analyze and optimize the processes. The purpose of this method is to establish the unknown relationship between the independent variables (input factors) and the process responses. Experiments were performed to fit a second-order model to the observations .The RSM designs are classified into Central Composite Design (CCD) and Box Behnken Design. In this work the Box Behnken design is used to fit second-order models to the response. CCD is not an appropriate choice of design because there is a concern regarding process constraints for testing each factor at extreme level. So, the Box-Behnken technique was selected to design the experiment, since its factorial combinations do not include any points at the vertices of the cubic region, and the resulting design is still rotatable. After the Box- 
Behnken design has been implemented, a regression model of the response in terms of independent variables is built to represent the relationship between the load, abrading distance, percentage of filler and the weight loss.

\section{Results and Discussion}

\subsection{Weight loss}

The graphical plots of weight loss as a function of abrading distances of unfilled (G-E) and TiC particulates filled (G-E-1 and GE-2) composites (abraded against 400 grit water proof $\mathrm{SiC}$ paper) at three different loads namely 5,10 and $15 \mathrm{~N}$ are shown in Fig. $3 \mathrm{a}$ to $3 \mathrm{c}$,respectively. From Fig. 3a-c, it is obvious that the weight loss of composites increases with increase in abrading distance and applied load. A lowest wear loss of $18.1 \mathrm{mg}$ was observed for G-E-1 composite at $25 \mathrm{~m}$ abrading distance and at $5 \mathrm{~N}$ load and a highest wear loss of $43.5 \mathrm{mg}$ was observed for G-E composite at $75 \mathrm{~m}$ abrading distance and at $15 \mathrm{~N}$ load. In addition, higher wear losses were noticed for all specimens tested at $15 \mathrm{~N}$ load. At the load of $5 \mathrm{~N}$, lower wear loss occurs because resin surface only was removed. On increasing the load from 5 to $10 \mathrm{~N}$, wearing out of certain amount of epoxy matrix and micro-fracture of glass fibers start taking place. This leads to increase in the overall wear loss. On further increasing the load from 10 to $15 \mathrm{~N}$ the glass fibers starts fracturing and spreads on the counter face. More crushing action of these glass fibers further increases wear damage on the specimen surface. However, the wear performance of G-E-1 showed higher wear resistance for all loads.
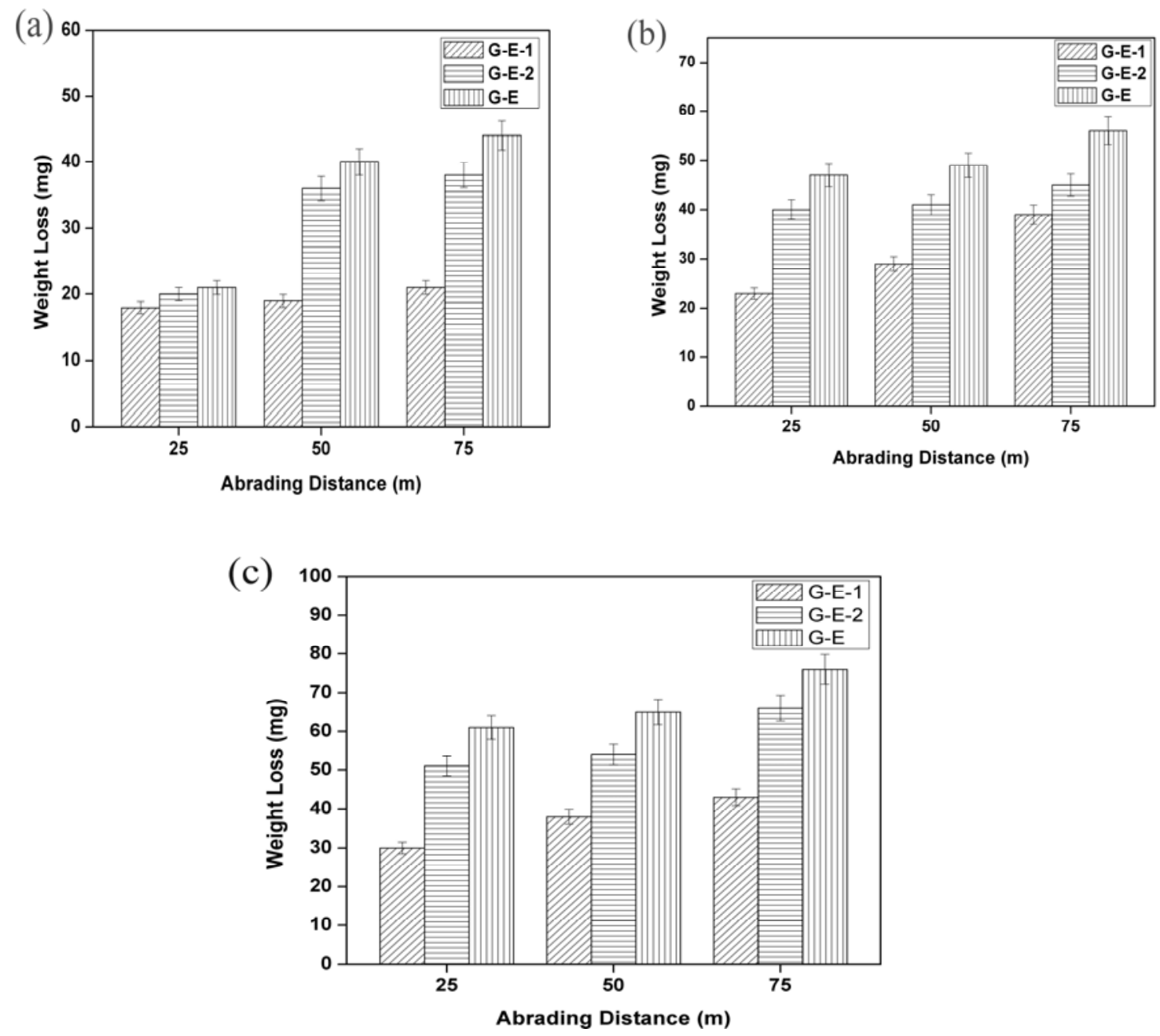

Figure. 3. Weight loss as function of abrading distance of G-E, G-E-1 and G-E-2 composites at (a) $5 \mathrm{~N}$ load; (b) $10 \mathrm{~N}$ load; (c) 15 $\mathrm{N}$ load

The TiC filled composite exhibited the higher wear resistance under different abrading distances. This behavior can be attributed to the presence of $\mathrm{TiC}$ particles on the counter surface, which act as a transfer layer and effective barriers to prevent large-scale fragmentation of epoxy. This is also evident from the micro-cracks and wears debris particles which were found in SEM pictures. 
Titanium carbide provides enhanced hardness and superior wear resistance, TiC filled composites exhibits lower weight loss. Among the composites studied, the wear resistance trend occurs in the following order G-E-1 > G-E-2 > G-E for three different loads of 5,10 and $15 \mathrm{~N}$. The TiC particles in the matrix prevent the fibers from damage by sustaining the applied load.

Unfilled G-E composites show an excessive surface damage due to its brittle nature and the dominant cutting wear mechanism. This is also evident from the SEM pictures. The wear data of the composites reveal that wear behavior strongly depends on the applied load (Srinath et.al, 2006). At higher abrading distances / applied load, the wear debris consists of shear deformed polymer matrix containing broken pulverized glass particles and $\mathrm{SiC}$ particles on the counter surface. The particles can either be lost from the contact zone or remain there for a fixed time as a transfer layer. The broken pulverized glass particles can also act as a third body abrasive leading to enhanced roughening of the counter surface. Hence the weight loss increases with increase in abrading distances/applied load. The weight loss of unfilled G-E is much higher than those of TiC filled G-E composite

An increase in load increases the contact stresses, the depth of penetration of the grit on the polymer surface and hence increase the weight loss. The wear behavior of $2 \mathrm{wt} \% \mathrm{TiC}$ filled composite showed a lower abrasive wear loss compared to the unfilled and 4 wt. \% filled G-E composites at all operating conditions.
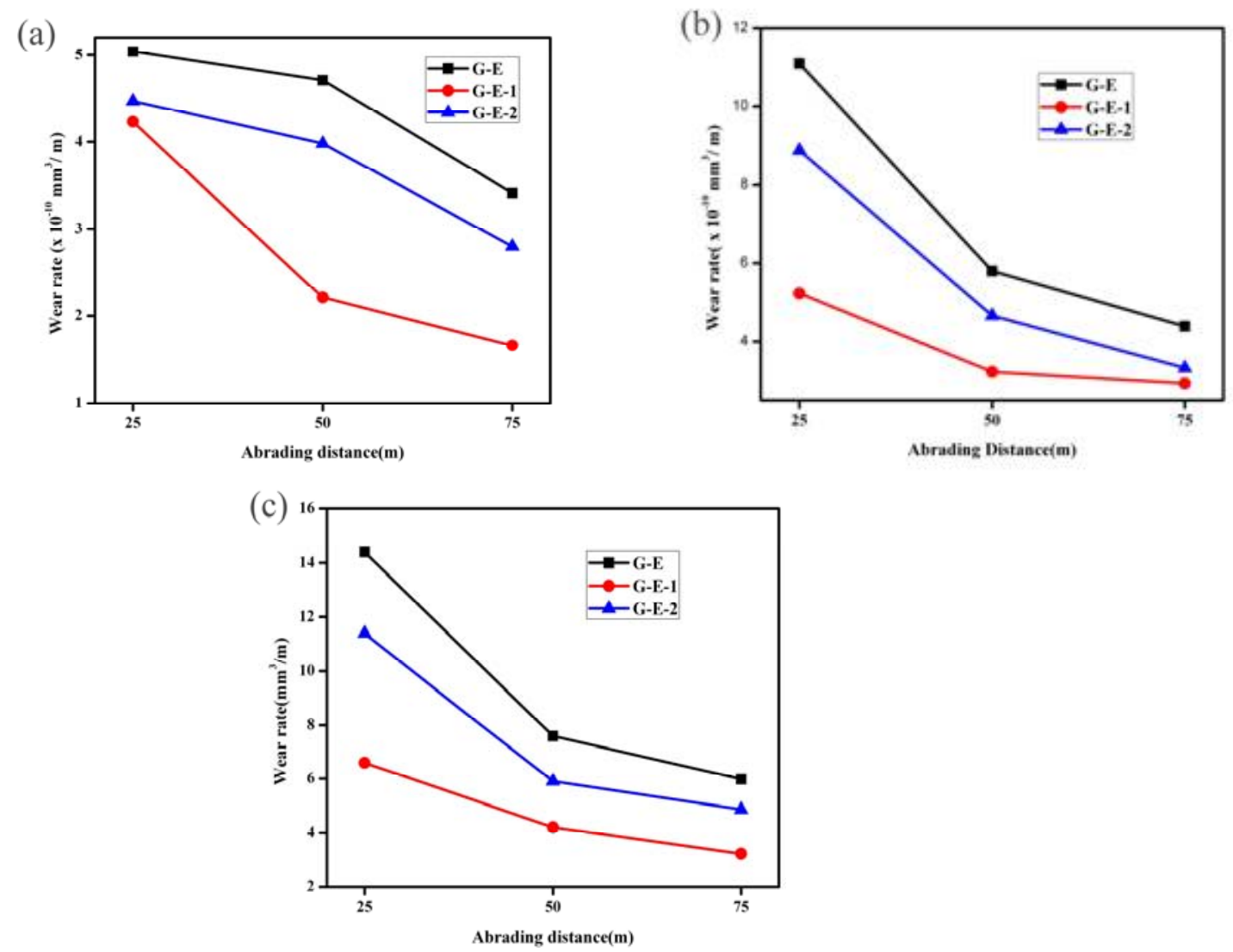

Figure 4. Wear rate as a function of abrading distance of unfilled and filled composites at (a) $5 \mathrm{~N}, \mathrm{~b}) 10 \mathrm{~N}$ and (c) $15 \mathrm{~N}$ abraded against 400 grit $\mathrm{SiC}$ paper .

The plot of wear rate versus abrading distance of composites abraded against 400 grit water proof SiC paper at three different loads namely 5, 10 and $15 \mathrm{~N}$ are shown in Fig. 4 (a-c), respectively. Fig 4 (a) reveals a drastic reduction in wear rate with an increase in abrading distances from $25 \mathrm{~m}$ to $50 \mathrm{~m}$. However, with further increase in abrading distances above $50 \mathrm{~m}$ the rate of reduction in wear rate starts decreasing. From the graph of wear rate, linear behavior was observed for the abrading distances from 50 to $75 \mathrm{~m}$. This is because when the specimen is in contact with the abrasive paper the wear rate is high. At higher abrading distance some of the worn particles clog the abrasive paper and slows down further wear rate. At lower abrading distance, low modulus polymer matrix (soft component) was exposed to abrasion and hence, high wear rate was observed. At higher abrading distance, high modulus glass fabric was exposed to abrasion, which show low wear rate. The glass fibers in the matrix are in contact with abrasive particles and change the surface characteristics of the specimen. Due to the exposure of fibers, less support was found for the epoxy matrix. The wear rates get decreased by increasing the abrading distance as shown in Fig (4 a-c). The wear rate significantly reduces with increase in abrading distance and applied loads. 


\subsection{Analysis of variance}

The RSM was performed using design of experiment package, Design Expert Version 8.0.4 was used to analyze the effects of the selected factors on the weight loss of the composites. As shown in Table 4, the analysis of variance (ANOVA) was determined to summarize the significance of each parameter in the test. The ANOVA also pointed out that the quadratic effect was useful to incorporate into the model. Moreover, the lack of fit test was insignificant $(>0.05)$, the model was adequate. The predicted equations (2) for weight loss in terms of actual factors:

$$
\begin{aligned}
& W=0.024+\left(9.638 * 10^{-3} * L\right)+\left(3.55 * 10^{-3} * D\right)-(3.993 * C)+\left(2.9 * 10^{-3} * L * D\right)+\left(2.665 * 10^{-3} * L^{2}\right) \\
& +8.05 * 10^{-4} * D^{2}+0.022 * C^{2}
\end{aligned}
$$

Table 4 ANOVA for weight loss

\begin{tabular}{cccccc}
\hline Source & SS & D.f & Mean square & F-value & P value \\
\hline Model & 0.00347 & 7 & 0.000435 & 124.83 & 0.0001 \\
L & 0.000743 & 1 & 0.000743 & 213.10 & 0.0001 \\
$\mathrm{D}$ & 0.000101 & 1 & 0.000101 & 29.00 & 0.0004 \\
$\mathrm{C}$ & 0.0001275 & 1 & 0.000128 & 36.57 & 0.0002 \\
$\mathrm{~L}^{*} \mathrm{D}$ & 0.0000336 & 1 & 0.0000336 & 9.65 & 0.0126 \\
$\mathrm{~L}^{2}$ & 0.0000299 & 1 & 0.0000299 & 8.58 & 0.0168 \\
$\mathrm{D}^{2}$ & 0.00000273 & 1 & 0.00000273 & 0.78 & 0.3994 \\
$\mathrm{C}^{2}$ & 0.00196 & 1 & 0.00196 & 562.36 & 0.0001 \\
Residual & 0.0000313 & 9 & 0.00000348 & & 0.2842 \\
Lack of Fit & 0.0000219 & 5 & 0.00000438 & 1.86 & \\
Pure Error & 0.00000944 & 4 & 0.00000236 & & \\
\hline Total & 0.00307 & 16 & & & \\
\hline
\end{tabular}

$\mathrm{L}=$ load, $\mathrm{D}=$ Distance, $\mathrm{C}=$ percentage of filler.

After the regression model was constructed, model adequacy checking was performed in order to examine whether the model is fit. The test for significance of the regression models, individual model coefficients and the lack of fit test are performed. The table 4 also shows the other adequacy measures $R^{2}$, adjusted $R^{2}$ and predicted $R^{2}$. Larger values of $R^{2}$ being more desirable. The entire adequacy measures are close to 1 , which is in reasonable agreement and indicate the adequacy of the models. Here the model terms are significant as it is less than 0.05 . The output shows that the model is significant with probability value (p-value) 0.0001 . The p-value for no lack of fit is 0.3856, which is larger than the reference limit $\mathrm{p}$ of 0.05 . The Model F-value of 126.75 implies that the model is significant. From the F-value it is evident that load is the most influencing parameter compared to abrading distance and percentage of filler. Adequate precision measures the signal to noise ratio. From the ANOVA analysis the contribution factors towards weight loss are found to be in the order of load (24\%), percentage of filler (4.155\%) and abrading distance $(3.27 \%)$.

Fig.5 $\mathrm{a}$ and $\mathrm{b}$ shows the interaction effect of load and percentage of filler on weight loss. As the load increases, the weight loss of the composite increases which is due to the damage of matrix and exposure of glass fibers (Suresha.et.al, 2008). The curvature effect of the graph shows that weight loss is minimum when the percentage of filler is $2 \%$ wt. This is because the addition of TiC increases the hardness of the composite and hence increases the wear resistance of the material. The interaction effect of distance and percentage of filler on weight loss is shown in Fig. $6 \mathrm{a}$ and b. The response graph infers that as the distance increases the weight loss of the composite also increases. The influence of abrading distance on weight loss compared to percentage of filler is not significant. The weight loss is found to be more when there is no amount of filler present in the glass-epoxy composites. So it is observed that filler addition is essential to reduce the weight loss and to increase the wear resistance. Maximum weight loss is obtained when the distance is at $75 \mathrm{~m}$ when compared to $25 \mathrm{~m}$ and $50 \mathrm{~m}$. From the contour plot, it was observed that $2 \%$ TiC filler filled composites exhibits minimum weight loss. Fig. $7 \mathrm{a}$ and $\mathrm{b}$ shows the interaction effect of distance and load on weight loss. At $5 \mathrm{~N}$ the weight loss is less, but it is more at 10 and $15 \mathrm{~N}$.As the abrading distance increases, the weight loss also increases. The graph clearly shows that as the applied load and abrading distance increases, the weight loss increase in all cases. As the applied load increases the matrix breaks away from the fiber surface which leads to detrimental effect on the glass fiber (Suresha.et.al, 2007). This resulted in higher weight loss at the maximum load. 
(a)

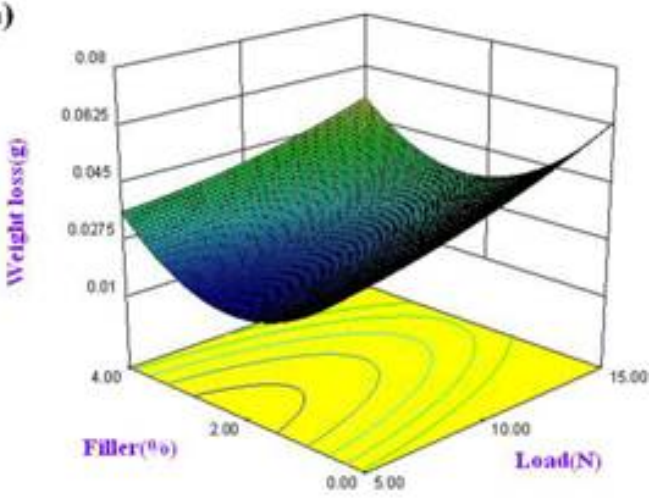

(b)

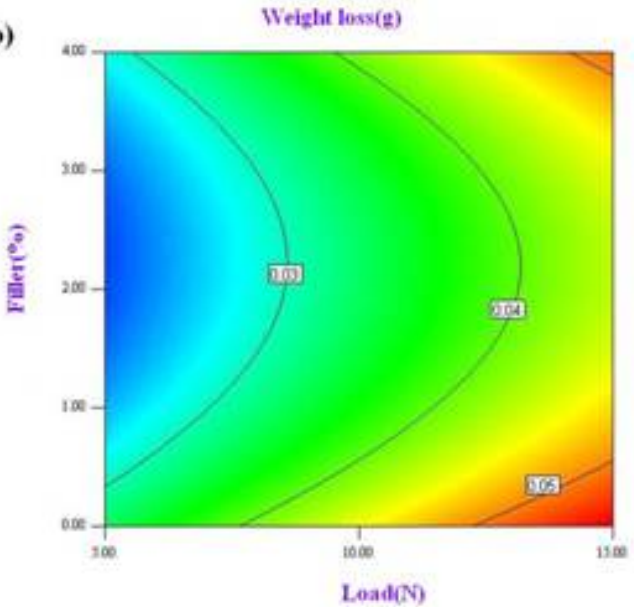

Figure 5 a)Response surface and b) contour plot showing the effect of load and percentage of filler on weight loss

(a)

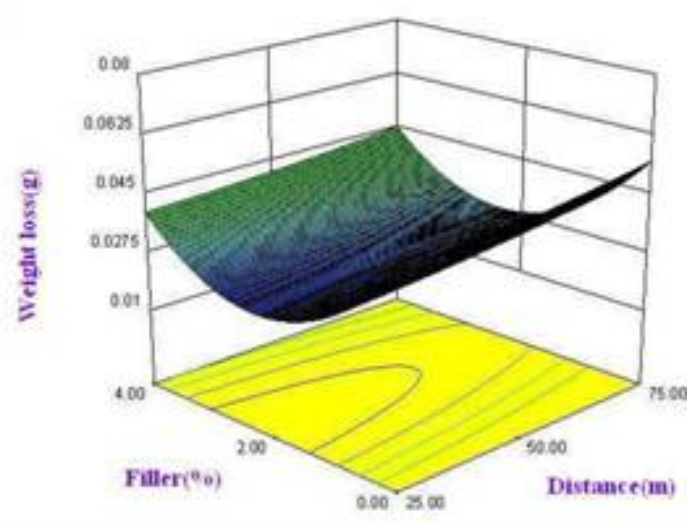

(b)

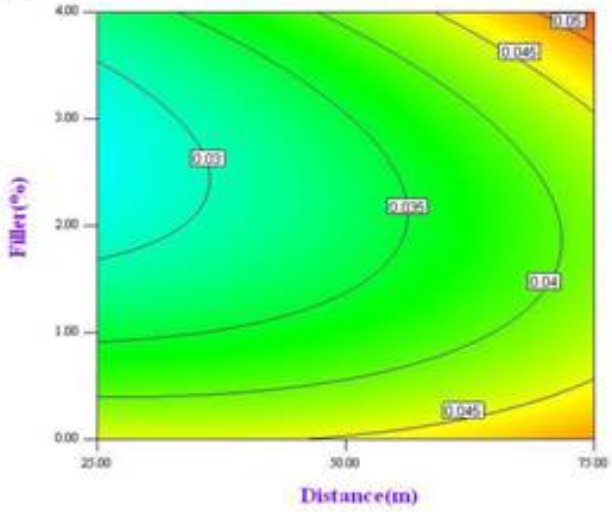

Figure 6.a)Response surface and b) contour plot showing the effect of distance and percentage of filler on weight loss

(a)

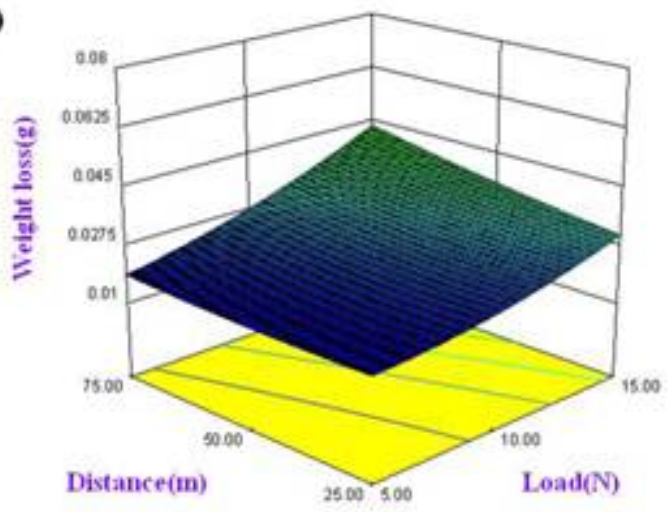

(b)

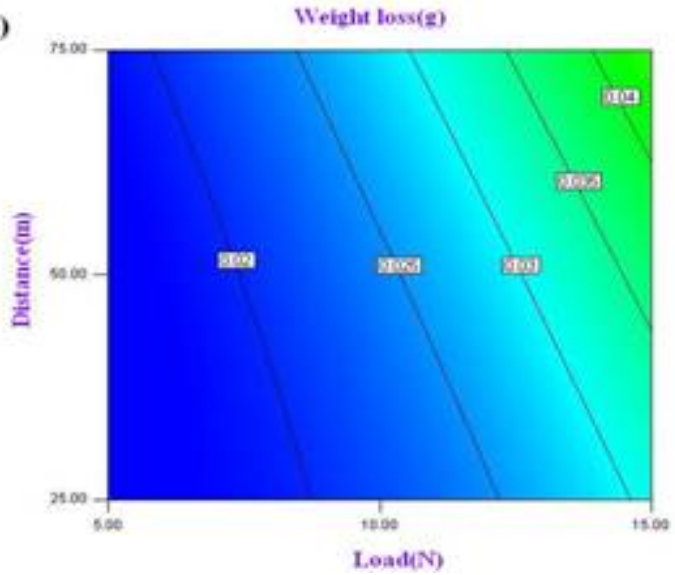

Figure 7.(a)Response surface and (b) contour plot showing the effect of load and distance on weight loss 


\section{Main Effects Plot - Data Means for C4}

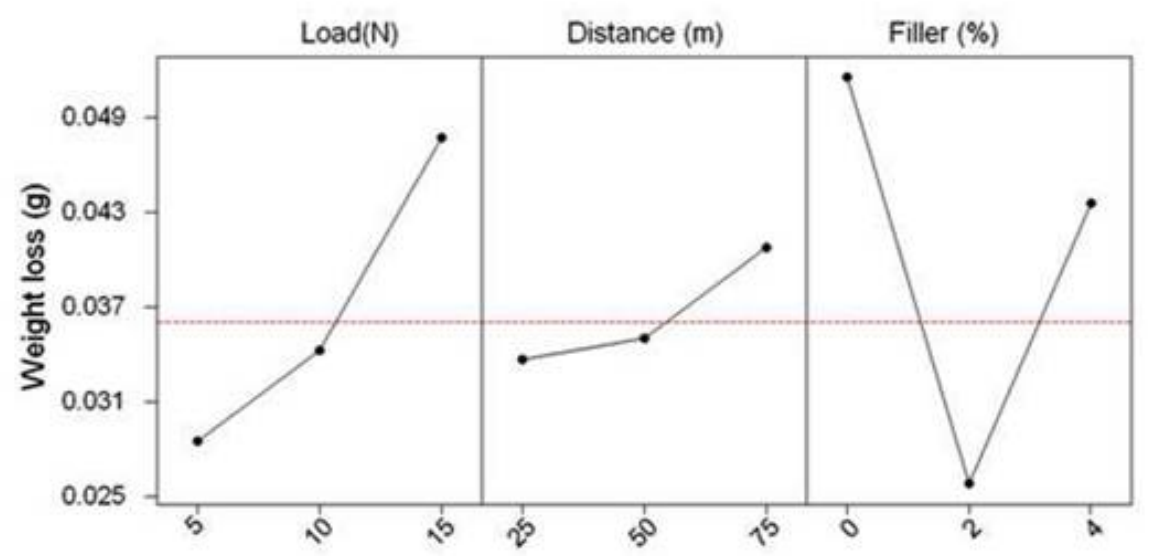

Figure 8. Main effects plot generated by MINITAB software.

The main effects plot generated by MINITAB software pertaining to ANOVA is shown in Fig.8. It can be inferred that minimum weight loss could be obtained when the percentage of filler is at $2 \%$, load values are low and distance is minimum. However at unfilled composites weight loss is high compared to filled ones.

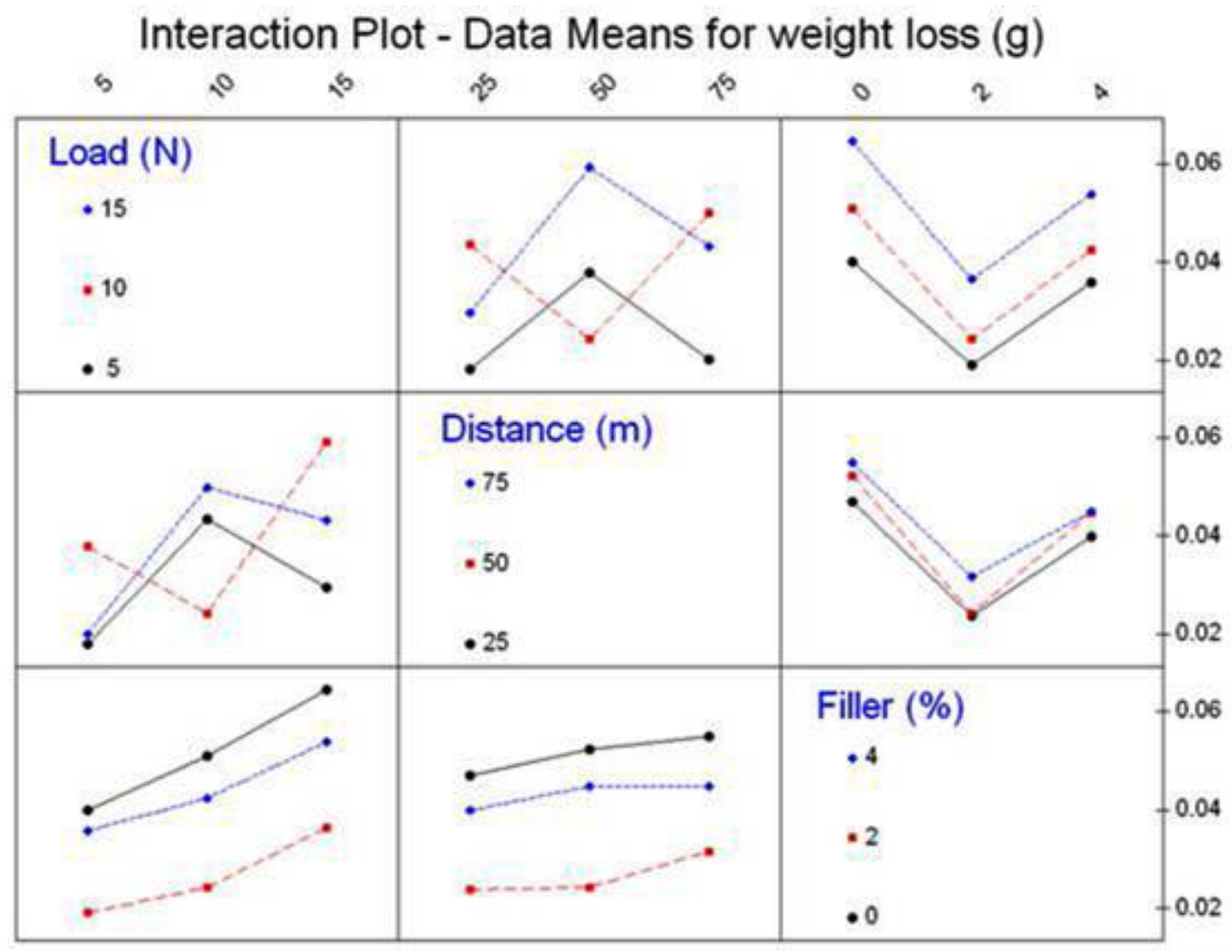

Figure 9. Interaction plot for the parameters generated 
The interaction plot between the parameters generated is shown in Fig.9.The interaction plot reveals that minimum wear rate is assured when the filler content is at $2 \%$, load is low and abrading distance is minimum.

\section{Analysis of worn surface by SEM}

The worn surfaces of the composites were examined using a scanning electron microscope (SEM) (S3000, V-1, and HITACHI). . Fig 10 a-c indicates the worn surfaces of the G-E, G-E-1, G-E-2 composites abraded against 400 grit SiC paper at higher load and sliding distance. The four steps in wear of polymer composites are (i) matrix wear, (ii) fiber wear, (iii) fiber fracture and (iv) fibrematrix interfacial debonding. Fig. 10a show the worn out features of unfilled G-E composite such as fiber cutting, matrix wear, fiber debonding and fiber crushing. The amount of observed damage is more in unfilled composite as compared to TiC filled composites. This is due to cutting action of sharp abrasive particles on the counter face at higher load and at higher sliding distance. Moreover, the glass fibers are exposed due to the removal of matrix and fiber cracks are produced at surface of the composite, which accounts for the poor wear-resistance of the unfilled glass fabric. Addition of TiC particles into epoxy matrix lead to increase in hardness of the composite. The material removal rate of the composite decreases with $2 \%$ wt TiC due to better shielding effect of $\mathrm{TiC}$ particles and its uniform dispersion in the epoxy matrix. Fig. $10 \mathrm{~b}$ indicates the $2 \mathrm{wt}$. \% TiC filled G-E composite showed less matrix damage. The TiC particles are uniformly distributed on the epoxy matrix and are found on the surface of the composite. These particles act as an effective barrier to prevent the damage of the fibers. Also micro cracking was observed on the surface of the matrix. In $4 \% \mathrm{wt} \mathrm{TiC}$ filled G-E composite, damage is more than $2 \mathrm{wt} \% \mathrm{TiC}$ and less than unfilled one. The amount of $4 \mathrm{wt} . \% \mathrm{TiC}$ particles does not support the protection of fibers and show separation of TiC particles from the resin matrix..Also the exposure of fiber takes place, leads to damage when the load is acting on it (Fig.10c). Hence it can be concluded that an increase in the percentage of filler material leads to less bonding between filler and matrix materials. To produce a good wear resistance, an optimum level of filler is required. By increasing the percentage of filler, the wear resistances get decreased and exposure of fibers was observed. The SEM pictures confirms the delamination of the fibers during wear, hence the delamination wear is dominant in the above composites.
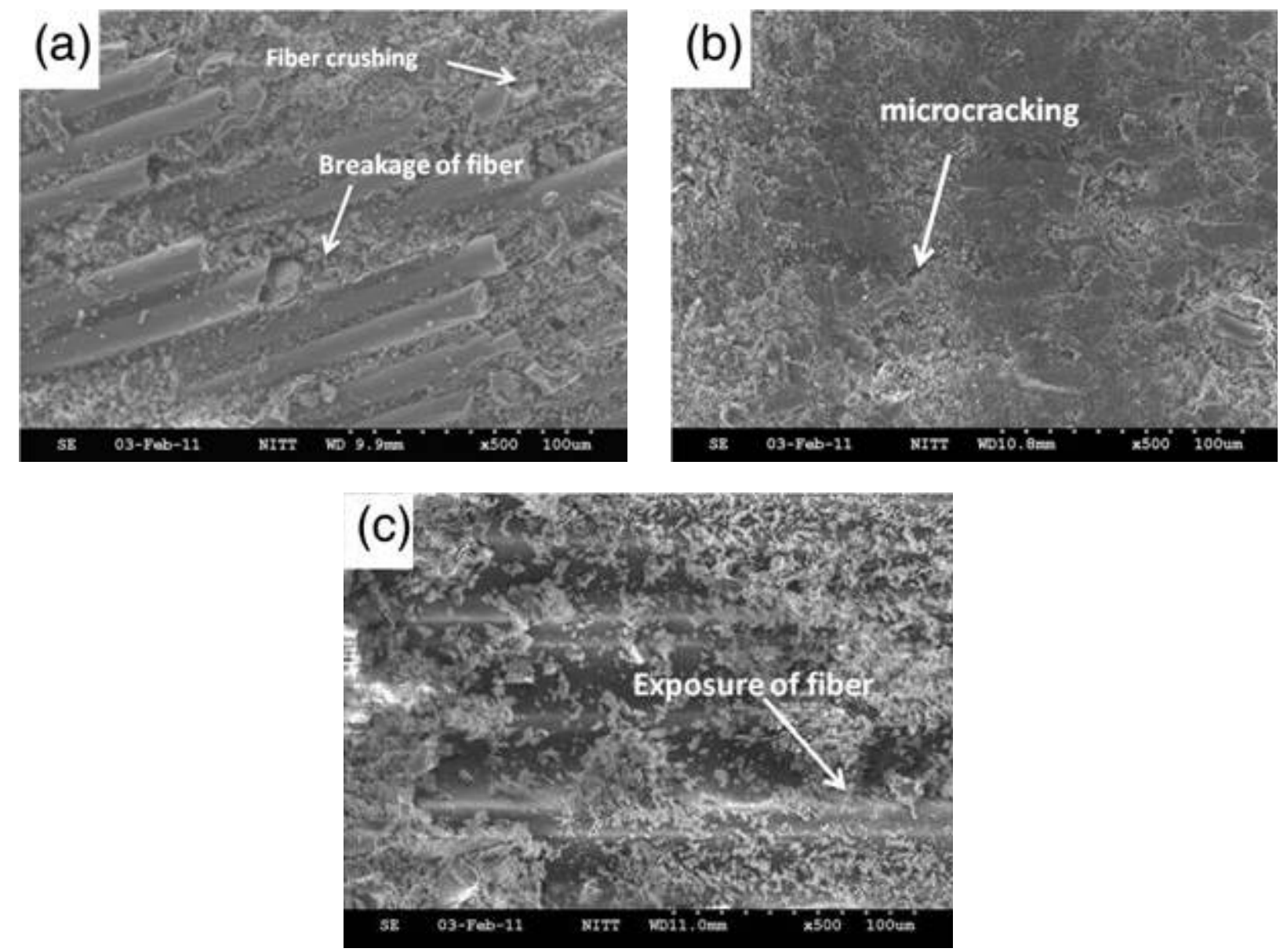

Figure 10: SEM images of worn surfaces (a) G-E composite; (b) G-E-1 composite; (c) G-E-2 composite 


\section{Conclusions}

Investigation on the effectiveness of $\mathrm{TiC}$ on the wear performance of composites has been reported. Among the composites, maximum enhancement in wear performance is observed in $2 \mathrm{wt}$. \% TiC filled glass-epoxy composites by the weight loss calculations. Delamination wear is found to be predominant wear mechanism in operation. The experimental observation coincides with the computational results obtained by Box-Behnken design using design of expert. From the ANOVA analysis the contribution factors towards weight loss are found to be in the order of load (24\%), percentage of filler (4.155\%) and abrading distance $(3.27 \%)$.

\section{References}

Bijwe. J, Indumathi. J, John Rajesh. J, Fahim. 2001. Friction and wear behavior of poly-etherimide composites in various wear modes, Wear; Vol. 249, pp715-726.

Chand. N, A. Naik, S. Neogi.2000.Three-body abrasive wear of short glass fibre polyester composite, Wear Vol. 242 pp38-46.

Chisholm. N, Mahfuzi .H, Rangari .V, Rodgers.R, Jeelani .S. 2004.Synthesis and mechanical characterization of carbon/epoxy composites reinforced with SiC nano particles. NSTI-Nanotech., Vol. 3, pp302-307.

Durand J. M., M. Vardavoulias, M. Jeandin. 1995. Role of reinforcing ceramic particles in the wear behavior of polymer-based model composites. Wear, Vol.181-183, pp 833-839.

Kishore, P. Sampathkumaran, S. Seetharamu, P. Thomas, M. Janardhana. 2005. A study on the effect of the type and content of filler in epoxy-glass composite system on the friction and slide wear characteristics. Wear, Vol. 259 pp. 634-641.

Mohan. N., S. Natarajan, S.P. KumareshBabu. 2011. Abrasive wear behavior of hard powders filled glass fabric-epoxy hybrid composites. Materials \& Design, Vol.32, pp1704-1709.

Srinath, R. Gnanamoorthy. 2006. Two-body abrasive wear characteristics of Nylon clay nanocomposites - effect of grit size, load, and sliding velocity. Materials Science and Engineering A, Vol. 435-436, pp 181-186.

Sahin Y., 2006. Optimal testing parameters on the wear behavior of various steels. Materials \& Design Vol.27, pp455-460.

Suresha.B, G. Chandramohan. 2008. Three-body abrasive wear behavior of particulate-filled glass-vinyl ester composites. Journal of Materials Processing Technology. Vol.200, pp 306-311.

Suresha. B, G.Chandramohan, PR. Sadananda Rao, P. Samapathkumaran, S. Seetharamu. 2007. Journal of Reinforced Plastics and Composites.Vol. 26, pp81-93.

\section{Biographical notes}

C. Anand Chairman is pursuing Ph.D in the department of Metallurgical and Materials Engineering, National Institute of Technology, Tiruchirapalli, India. His research area is nano particles reinforced polymer composites for aerospace and naval applications.

Dr. S. P. Kumaresh Babu is working as Associate Professor in the Department of Metallurgical and Materials Engineering, National Institute of Technology Tiruchirappalli India. He has more than 15 years of experience in teaching and research. His current area of research includes metal casting, welding, corrosion and composites. He has published more than fifty papers in referred international journals /conference proceedings.

Dr. Muthukannan DuraiSelvam is Associate Professor in the Department of Production Engineering, National Institute of Technology Tiruchirappalli, India. He has more than 10 years of experience in teaching and research. His current area of research includes laser cladding, liquid impact erosion, synthesis of nano composites, process optimization. He has published more than fifteen papers in referred international journals /conference proceedings.

K.R. Balasubramanian is Assistant professor in the department of mechanical Engineering, National Institute of Technology Tiruchirappalli, India. He has more than 10 years of experience in teaching and research. His current area of research includes thermal engineering, turbo machines, CAD/CAM, CFD, Welding. He has published more than twenty papers in referred international journals /conference proceedings.

Received June 2011

Accepted June 2011

Final acceptance in revised form June 2011 